\title{
Historiography of Developing the Issue of the Information Skills in the Social and Cultural Space of the Further Education
}

\author{
Kucher Tatyana Pavlovna ${ }^{1} \&$ Kolyeva Natalya Stanislavovna ${ }^{1}$ \\ ${ }^{1}$ North Kazakhstan State University named after Manash Kozybayev, Petropavlovsk, Kazakhstan \\ Correspondence: Kolyeva Natalya Stanislavovna, North Kazakhstan State University named after Manash \\ Kozybayev, Petropavlovsk 15000, Kazakhstan.
}

Received: January 16, 2015 Accepted: March 6, 2015 Online Published: May 28, 2015

doi:10.5539/ies.v8n6p217 URL: http://dx.doi.org/10.5539/ies.v8n6p217

\begin{abstract}
The paper deals with the problem of historiography, presented in three stages: the first stage (50-90s of the XX century) is characterized by the introduction of a scientific apparatus expertise creating the preconditions of differences between concepts, the release of an independent direction of history of social and cultural activities. In the second phase (90-2000s) pedagogical research appears on the problem of the formation of different types of competence (professional, informational, social, psychological, communication, legal, social, cultural and educational). The methodology of historical and educational research created and refined conceptual framework of social and cultural activities. The third phase (2000 to the present) is characterized by comprehensive research in the field of information competence, substantiation of theoretical and methodological framework, the researchers conducted an analysis of the phenomenon of leisure activities from the standpoint of the theory of culture, an emphasis on cultural needs, which are the motivation for leisure-time activities.
\end{abstract}

Keywords: historical and pedagogical analysis, information competence, teenagers, socio-cultural educational environment

\section{Introduction}

Considering the key aspects of the information competence development in social and cultural space of additional education and putting forward their own proposals to deal with it, it is necessary first of all to consider the history of the test questions formation. As it is known, understanding of the essence of a phenomenon is impossible without studying its genesis. When constricting the historiography of the problem we face with the problem of synchronization of three historical processes; so we recommend the following logic. Firstly, to consider the historical aspect of the formation and development problem of information competence approaches in education. Secondly, to study the genesis of social and cultural space of additional education.

Historiography is treated as "chronologically complete and systematic collection of information about the development of scientific problems" (Yakovlev, 2006). Construction of historiography, objectively representing the trajectory of formation of the investigated problem, identifies promising directions of scientific research and assessment of the degree of elaboration. It necessarily implies the following tasks:

1) The base of the beginning of the genesis of the problem;

2) Identification of the unit of the historical process;

3) The definition of substantial filling stage of development of the problem under study;

4) Fixation of the problem development periods and dating their shift.

Defining the specifics of the meaning of the studied "information skills" and "social and cultural educational space" concepts could be carried out by the integrated use of the theoretical and empirical research methods and involves reference to the historical and teaching analysis and evolution of these concepts (specifying the main stages of the process, its description and reviewing the genesis of the centering concepts at each stage). The review of the methodological and psychological literature, as well as thesis researches and serial publications on education, conducted as part of our study, has made it possible to infer, that during its development the information technologies, as well as the concepts of "skills", "social and cultural space" have gone through three main stages. 


\section{Method}

Stage I (50-90s of the XX century). Some scientists believe that the skills-oriented education was developed in 50-60s in America, within the general framework of the "skills" concept, proposed by N. Chomsky (the University of Massachusetts) in relation to the linguistic theory and the transformational grammar. Chomsky N. has made a fundamental difference between the language skills (the speaker's or the listener's knowledge of his language) and the language use (the actual use of language in particular situations).

In the middle of the XX century White R. used the concept of skills in order to describe the features, associated with the excellent performance of work and the highly motivated individuals, finding out, that the successful and effective performers differ from the less successful ones by not only and not so much knowledge, but effective self-regulation, self-consciousness and the developed social skills (White, 1959; Spencer, 1983; Klemp, 1977). In the 70s Skinner introduced the competency approach in order to solve the new problems by people in unknown situations (McClelland \& Dailey, 1974; Schneider et al., 1981; Raven, 1984; Shchedrovitsky, 2005).

Some researchers consider Shatsky S.T. and his followers, the didactic school of Skatkin-Lerner-Krayevsky, the representatives of the system and mental activity education approach of Shchedrovitsky P. G. et al as the founders of the competency approach in the Russian education (Zimnyaya, 2003).

In the late $80 \mathrm{~s}$ of the XX century the Russian scientists (Gershunsky, Zimnyaya, Kolpakova, Markova, Pechenyuk, Shakurov et al.) considered the concept of "skills" as the personal ability to properly use the acquired knowledge, abilities, skills and experience in solving practical problems in normal and abnormal situations. They identified three stages of developing the competency approach in education: the first one (1960s-1970s) is associated with introducing the "skills" category into the research framework, providing the prerequisites for differentiating the concepts of the competence/skills category; the second one (1970s-1990s) is correlated with the use of the competence/skills category in the theory and practice of language teaching, competence in control, guidance, management, teaching the communication skills; and the third one (since 1990) is characterized by studying competence as a scientific category in relation to education.

Consider further the history of developing the social and cultural space and the social and cultural activity.

The literature review showed that during the period from 1945 to 1993 the social and cultural activity was known as the cultural and educational work. Since 1980 the theory of the cultural and educational work has been studied at the interface of two sciences - the education and the theory of the ideological activity. Understanding the cultural and educational work as the club activity has been established. The researches by Andreeva and Ryabkov are devoted to the general historical studies of the cultural and educational work.

During the 70-80s the "leisure activity" concept was considered in the system of "working", "non-office" and "off hours" categories, and was defined as the unregulated, voluntary activity. The another point of view was reduced to defining the leisure activity as the activity intended for the all-round development of a person, the emphasis was made on the diversity of activities outside the occupational, family and living field of activity (Gurin, 2011).

In the 80s the fundamental studies of the off hours issues included the works by Yevteyeva and Triodin. In their works the psychological and education framework of using off hours by a person is thoroughly examined, the interests and spiritual needs of different social groups are analyzed, the specific structures of leisure activities are disclosed, and the relation between the club and out-of-club leisure activity types is identified.

Prior to the 1990s the cultural leisure activity was studied in the context of the social and everyday life only, as the means of the ideological education (within the history of the cultural and educational work), as well as in the context of opposition to working, non-office and off hours (Smolyaninova, 2000). The history of the social and cultural activity was identified as a separate area from the early 1990s.

As a result of the conducted analysis, the following conclusions could be drawn:

1) This stage is characterized by introducing the competence/skills category into the research framework, understanding the differences between the concepts.

2) Understanding the cultural and educational work was established, the history of the social and cultural activity was set up as a separate area.

Stage II (90-2000s of the XX century). The intensive study of the competence/skills phenomenon is typical for this stage in the domestic science. The review of the scientific literature has shown that the issue of developing the competence is multidisciplinary, as its different aspects are considered in philosophy, psychology, education, sociology, and management. The studied "skills" concept is ambiguous, the opinions in the researchers' works 
on the definition and content of the examined concept are rather dispersed. Note the great contribution made to the development of the competence issues in general and the skills (competencies) in particular by the following Russian researchers: Alexeyeva, Kuzmina, Markova, Mitina, Petrovskaya, Sivkova, and Shablygina et al.

The second stage of studying the competence/skills phenomenon is characterized by the occurrence of the works by Markova, where in the general framework competence becomes the subject of a special comprehensive consideration. During this period Mitina continued to study the research by Petrovskaya as to focus on the social and psychological, as well as communicative aspects of the teacher's competence, where the complex integrative nature of competence was emphasized.

The scientific publications and thesis researches of the concerned period: were focused on the occupational, informational, social, psychological, communicative, legal, social and cultural, and teaching competence. The variety and diversity of the researches in this field show the urgency of concerned issue. Due to the specifics of the activity performed, each competence type has its own peculiarities, though in their structure the common elements, such as knowledge, abilities and skills, which are reasonably required, could be found in their structure.

Let's consider the history of developing the social and cultural activity and the social and cultural space at this stage.

The review of the education literature of the 90s showed, that the social and economic situation in the country had influenced the development of the cultural and educational work:

- The scope, trend, and name of the cultural and educational work on "social and cultural activity" were changed;

- The cultural and leisure activity was one of the main trends.

This influenced the scientific approaches, classification, and the essence of functions of the cultural and educational work, the social and cultural activity.

In the 90 s the theory and practice of the cultural and leisure activity was enriched by the studies of Zharkov, Kiseleva, Krasilnikov, Lugansky, Poplavsky, Surtaev, and Titov. In Titov's B.A. studies the process of the children's, adolescents' and young adults' socialization is entirely considered for the first time within the field of the leisure activity. Surtaev V.Y. explored the specifics of the youth leisure activity, identified the social and teaching conditions for facilitating the cultural and leisure activity of the young people (Ryabkov, 2009).

During this period the issues of the social planning of the leisure centers and the regional cultural policy, as well as establishing the cultural and leisure programs, become urgent. The researches by Birzhenyuk, Zhezhko, Markov, Panova, Rozin, Falin et al. have become very important for solving the indicated issues (Ryabkov, 2009).

As a result of the conducted analysis, the following conclusions could be drawn:

1) The teaching (?) researches, devoted to establishing the occupational, informational, social, psychological, communicative, legal, social and cultural, and teaching competence occur. Each competence type has its own peculiarities, though their structure includes the defined common elements, namely knowledge, abilities and skills.

2) This period is characterized by establishing the scientific basis for the general theory of the social and cultural activity, developing the methodology for historical and teaching researches, as well as improving their conceptual framework.

Stage III (from the early XXI century to date). This stage could be called the stage of approving the competency approach, which is characterized by the intense use of the competence/skills categories in education. In 2002, numerous discussions of the competency approach were held. During this period the current model of the competency approach in the context of both implemented and the alternative approaches, internal contradictions and problems, as well as the used ideas and concepts were defined.

Khutorskoy believes, that the ideas expressed at that time, including those presented at the IX All-Russian Research-to-Practice Conference on the "Development of Education: the Key Competences and their Development" has made it possible to define a generalized image of the most important elements of the competency approach in the domestic education.

Hence, Khutorskoy distributes the educational skills into the same levels, as the education content:

- $\quad$ The key skills (implemented within the meta-subject and cross-subject content); 
- The general subject skills (implemented within the content, which is integrative for a set of objects, the education sector);

- The subject skills (established within particular subjects).

The issues of the competency approach in education are considered also in the following thesis researches: "Designing the Education Process at the Teacher Education University upon the Competency Approach" (Bespalova, 2011), "Preparation of the Competitive Competency Approach" (Tretyakova, 2010), "Competency Approach to Mathematics and Scientific Subjects Delivered as the Non-Majors" (Mishakina, 2009), and others. The works, devoted to studying the information literacy, the culture of students; developing the information outlook of the students and teachers; designing the information and learning environment; considering the teaching conditions, which contribute to establishing and developing the information competence of the university students and teachers, occur. For example, "Information Culture as a Factor of the Interaction between the Social and the Individual" (Vodopyanova, 2001), "Establishing Information Culture of the Teacher's Training School and College Students" (Andreyeva, 2003), "The Process of Developing the Information Competence of an Upper-Former" (Trishina, 2005)," The Teaching Conditions of Managing the Establishment of the Information and Technological Competence of a Student in a Comprehensive School" (Martynova, 2007), and "Establishing the Information Competence of the Students in the Context of the Specialized Training in a Comprehensive School" (Hurum, 2010).

The third stage in developing the social and cultural activity is characterized by occurring the concept, which determines the efficiency of this kind of activity. The cultural institution performance is considered in the context of the social and economic efficiency. The current social and cultural performance of the cultural institutions depends on to what extent they are ready to act under the current conditions, to understand and define their place in the society, and to find their client. It seems to be possible due to the project activity, extending the list of the services rendered, searching for the extra-budgetary resources, developing the performance criteria according to the list of services. The concept of "cultural service" is put into the social and cultural activity. Assessing the quality of service rendered is a key element in assessing the cultural and leisure institution performance. It allows adjusts the trends in the institution development, setting target orientation of services and providing the feedback required for the system, which is sustainable and able to develop (Ryabkov, 2009).

During this period the education materials and various textbooks (Shamsutdinova, Kiseleva, Krasilnikov and Zharkov, are published, where new scientific approaches to the functions of the social and cultural activities, as well as cultural and leisure activities, are set forth while retaining the particular elements of the earlier studies. Krasilnikov identifies the following functions of the social and cultural activity: the communicative; informational and educational; culture-making; and recreative ones.

The main results of the third stage are:

1) Understanding the need for the targeted information skill established by the researchers, hence, encouragement of the researches in the field of the information skill development, reasoning of the theoretical and methodological framework.

2) The analysis of the leisure activity phenomenon in terms of the cultural theory has been conducted by the researchers, making the emphasis on the cultural needs, which are the reason for the leisure activity.

\section{Results}

Thus, historiography of the problem was presented on the basis of historical and pedagogical analysis and is defined as a set of historical research pertaining to any issue. In the historiography of the information competence development problem in the social and cultural space of additional education we have allocated three main stages:

- The first stage (50-90s $\mathrm{f}$ the XX century).

- The second phase (90-2000s of the XX century).

- The third phase (from 2000 to the present time).

\section{Discussion}

Analysis of foreign and domestic works on the issue of competence approach confirms that the current lack of common definitions of basic concepts of competence and competency leads to a controversial analysis of the education processes.

In the dictionary of the Russian language the term "competence" is interpreted as "the area of issues in which 
someone is knowledgeable" (Dictionary of the Russian language, 1981). Also Ozhegov in his dictionary of the Russian language (Ozhegov, 1999) defines this word as follows: "competent means knowledgeable, informed, and authoritative in any field". "Competence": 1) The range of issues in which someone is knowledgeable; 2) The terms of office of someone's rights. "Competence" is originated from the Latin word compete, which means that I achievement, compliance, going up.

Note that the term "competence" is a synonym to a number of concepts, such as "knowledge" (knowledge, literacy, awareness), "preparedness" (preparation, training, prowess), "readiness"; competently means with skill, expertly, professionally and skillfully, etc. (Pedagogy: Big modern Encyclopedia, 2005). Thus, competence is a set of specific professional or functional characteristics. Competence is a personal characteristics, reflecting the willingness and ability of a person to effectively solve problems that arise in front of him in the course of business (Zimniaya, 2003).

The notion of "information competence" is closely related to the acquisition, processing and transmission of information, transforming it into knowledge, using information resources and technology activities in the information society.

At the present stage of development of pedagogy, many scientists (Akulepko, Almazova, Balykhin, Berishvili, Dzugoeva, Zaitsev, Selevko, Semenov, Tairova, Tolstoy, and others) define the concept of "information competence" ambiguously. Based on the analysis, we have identified such attribute of information competence characteristics that make it unique, distinctive, independent phenomenon:

- The ability to search for, analyze and select relevant information, organize, convert, store, and transmit it using real objects and information tehnology;

- New literacy, which includes the ability to active independent human information processing, adoption of new solutions in emergency situations with the use of technological means;

- A person's ability to search for, select, analyze, organize, represent and transmit information;

- Integrative quality of the personal education system of knowledge, skills and ability of the subject in the field of information and communication technologies and their utilization, as well as the ability to improve their knowledge, skills and adopt new solutions in a changing environment or unforeseen situations with the use of new technological resources;

- Individual mental state, bringing together theoretical knowledge about the sources of information and the ability to work with the information provided in various forms, as well as an opportunity to use new information technologies;

- Combined individual-psychological education on the basis of integration of theoretical knowledge and practical skills in the field of innovation technologies and a particular set of personal qualities;

- Professionally significant qualities, which consist in mastering the basic skills to work with information;

- Set of personal qualities of the subject, which allow one to achieve high results in the activities of the rapid changes of information infrastructure in unity with the global trends of information behavior.

Expanding the scope and content of the information competence concept from substantive skills to the ability, the quality of the individual to its state education in the structure of personality; from subject to professional activities reflects the responsiveness of the conceptual apparatus of pedagogy at the increasingly complex requirements of the information society.

Thus, under the jurisdiction of information we will understand integrative quality of the person, which is the result of reflection processes of selection, assimilation, processing, transformation and generation of information in a particular type of subject-specific knowledge and experience contribute to the establishment of information and communication activities; system updating this experience motivates willingness and ability of adolescents to transform information into knowledge with the prospect of self-education and self-realization in today's information society. In this definition, the sequence of actions can be traced to the information that allows us to structure the development process of development study competence of in adolescents, with its styling.

How to confirm the results of the research environment, expanding opportunities for the development of information competence of adolescents is a socio-cultural space in terms of additional education. Study of socio-cultural space engaged ethnographers and anthropologists, educators and sociologists, historians, linguists, art historians, and philosophers. Analysis of teaching and popular scientific publications suggests that each generation builds its own world, i.e. socio-cultural space, which has its own value system. It is in this space where the individual is identified as an individual and as a social subject. This should draw attention to the fact 
that the factors favoring the formation of a teenager should take into account the nature of his own personality and its own, the active principle (Cultural and educational space of contemporary human: a collective monograph, 2010).

Spengler, Toynbee, Chuchin-Russians, and Panarin believe that the socio-cultural space is the process and the result of the deployment of culture in time and space and is related to social parameters; this civilizational continuity with broad spatio-temporal framework that includes all the most complicated genesis processes, distribution and functioning, which occur randomly and not by chance, but are subject to certain logic and are determined by specific parameters (Berestova, 2004).

The phenomenon of social and cultural space manifests a wide variety of processes of interaction between different social structures, resulting from human activity. This space is multidimensional, it is regarded to living environment and socialization, group, and society. In this space there are relations, there is a transfer of values of society, carried out by social and cultural activities of adolescents (Shamsutdinova, 2001).

Selivanova gives three options for defining the socio-cultural space:

1) Socio-cultural space is a pedagogical reasonably organized environment surrounding certain child or many children. Structural unit of the space is a professional team of educational, cultural or other institutions, as the main mechanism for the creation of this space is the interaction groups, driven by single pedagogical objectives, principles and approaches to education.

2) Socio-cultural space is treated as a part of the environment in which dominates a particular pedagogical lifestyle. In this case, the interaction of all participants is determined by the most perfect model of lifestyle, with underestimating the subjective role of the child.

3) Educational space is represented as a dynamic network of interconnected pedagogical events generated by the efforts of social subjects at various levels (collective and individual), which advocates an integrated of personality development of human condition - both adults and children. In this case, the mechanism for creating social and cultural space becomes an "event" for children and adults, where their joint activity is a key technology point.

Some researchers (Krylov, Listvin, Manuylov, Selivanov, Titov, Trukhacheva, Filonov, Shipunov et al.) introduced the concept of "educational social and cultural environment", which consists of the system of key determinants of education and human development: the people who influence the educational process; socio-political system of the country; natural and socio-cultural environment (including pedagogical culture medium); the media; and random events.

Evsikova (2009) considers socio-cultural environment as a set of external conditions of educational institutions functioning, including especially the concrete historical situation, the nature of the processes in key areas of society, a system of regulatory requirements for the organization of educational process and its changes.

Socio-cultural space, creating by human, receives an independent existence. Its development is largely contributed to the latest communication systems that create the effect of "simultaneity" on a global scale: through satellite communication system one can be a witness of any event, regardless of where it occurred. Inner world of a person reflects all the troubles in the society development of society, the state of spiritual culture (cultural and educational space of contemporary human: a collective monograph, 2010).

Krylova identifies the following characteristics of the socio-cultural educational space:

- Integrity of education (implementation of a comprehensive training and education goals);

- Access to education (population accounted for lifestyle, cultural and educational needs, the level of wealth, geographical location of educational institutions, and so on);

- Ethno-cultural character (the possibility of maintaining national culture: traditions, norms, and values);

- Labor practice-orientation; continuity of education (possibility of extension).

In terms of additional education, socio-cultural space realizes maximum demands and needs of adolescents through the following (Pedagogy social and cultural spheres: history, theory, practice: the collection. Sci. Art. 2001):

- Providing psychological comfort;

- Ensuring the personal importance of teenagers giving everyone a chance to open himself as an individual, as a person; 
- Guarantying of creative development for the forces and interests at their own pace;

- Managing the relationship of all subjects of additional education on the principles of real humanism;

- $\quad$ Urging teens to self-development and self-education, self-esteem and self-awareness.

Analysis of certain social and cultural space, as well as typological features allowed us to formulate a operational definition that in our view most closely, describes the nature and purpose (of what).

Thus, the socio-cultural educational environment is a factor, which contributes to the socialization of adolescents, reflecting their cultural and educational needs and creatively applied focus of information products.

\section{Conclusion}

The analysis of the foreign and domestic researches on the issue shows, that nowadays the education faces a rather complicated problem, which is solved by the researchers quite ambiguously, when defining the unified interpretation of concerned concepts; thus, there are no conventional definitions. It is obvious that the problem needs resolution, i.e. a study of laws, principles, and mechanisms, as well as individualization and differentiation of conditions of information competence formation in students on the basis of the relationship and interdependence between the development and formation of the desired characteristics, along with search for other means of increasing the level of information competence formation.

\section{References}

Berestova, T. F. (2004). Unity of information space: Theoretical and methodological aspect. A single information space of Russia: federal and regional components: International materials. Conf. GG Krasnodar-Gelendzhik.

Evgenyeva, A. P. (1981). Russian Dictionary yazyka, 2(4), 284. Moscow: Russian language.

Evsikova, N. I. (2009). Influence variativnoj educational environment for emotional and personal development of the student in the full cycle of schooling ( $\mathrm{PhD}$ thesis, pp. 278). Moscow.

Golub, J. G. (2010). Cultural and educational space of modern man: A collective monograph (p. 167). Saratov Saratov source.

Gurin, N. A. (2011). Young Scientist. The History of the Social and Cultural Activity as a Separate Research Area, 11(2), 42-45.

Klemp, G. O. (1977). An Analysis of Leadership and Management Competencies of Commissioned and Noncommissioned Naval Officers in the Pacific and Atlantic Fleets. Boston.

McClelland, D. C., \& Dailey, C. (1974). Professional Competencies of Human Service Workers. Boston.

Ojegov, S. I. (1999). Dictionary of Russian language: 80000 words and idiomatic expressions (pp. 944). Russian Academy of Sciences. Russian Language Institute. VV Vinogradov. Moscow: Azbukovnik.

Rapatsevich, E. S. (2005). Pedagogy: A modern encyclopedia (p. 720). Moscow: Modern Word.

Raven, J. (1984). Competence in Modem Society: Its Identification, Development and Release. Oxford: Oxford Psychologists Press.

Ryabkov, V. M. (2009). The Historiography of the Teaching Theory of the Social and Cultural Activity (The Second Half of the XX-Early XXI Centuries): Ed. D. Thesis (p. 470). Chelyabinsk.

Schneider, C., Klemp, G., \& Kastendiek, S. (1981). The Balancing Act: Competencies of Effective Teachers and Mentors in Degree Programs for Adults. Boston.

Shamsutdinova, D. V. (2001). Social and cultural integration of the individual in the field of leisure (p. 256). Kazan: KSU.

Shchedrovitsky, P. G. (2005). The Sign and the Activity: in 3 Vol. Vol. 1. The Sign Structure: Essences, Meanings, Knowledge: 14 Lectures (p. 463). Moscow: Oriental Literature Publishers.

Smolyaninova, O. G. (2000). The Innovation Methods of Student Training Based on the Case Study Method (pp. 103-111). Moscow: Innovations in the Russian Education, HVE.

Spencer, L. M. (1983). Soft Skill Competencies. Edinburgh: The Scottish Council for Research in Education.

White, R. W. (1959). Motivation Reconsidered: the Concept of Competence. Psychological Review, 66, $297-333$. http://dx.doi.org/10.1037/h0040934

Winter, I. A. (2003). Key competencies-a new paradigm of education result. Higher education today, 5, 34-42. 
Yakovlev, E. V. (2006). Pedagogical concept: methodological aspects of building (p. 239). M.: humanities. ed. VLADOS center.

Yaroshenko, N. N., \& Litovkin, E. V. (2001). Pedagogy of the socio-cultural sphere: The history, theory and practice: The collection. scientific. Art. (p. 193). Ryazan: REI MGUKI.

Zimnyaya, I. A. (2003). Key Skills-Are the New Paradigm of the Education Results. The Today's Higher Education, 5, 34-42.

\section{Copyrights}

Copyright for this article is retained by the author(s), with first publication rights granted to the journal.

This is an open-access article distributed under the terms and conditions of the Creative Commons Attribution license (http://creativecommons.org/licenses/by/3.0/). 